\title{
Thermoelectrical characterization and comparative analysis of three finite element models of a MEMS thermal sensor
}

\author{
M. Gómez Franco*, A. Sauceda Carvajal \\ Depto. Ing. Eléctrica y Computación, Instituto de Ingeniería y Tecnología, Universidad Autónoma de Ciudad Juárez \\ Cd. Juárez, Chi. 32310, México \\ A. Ramírez Treviño \\ Control Automático, Centro de Investigación y de Estudios Avanzados del Instituto Politécnico Nacional (Guadalajara) \\ Zapopan, Jal. 45019, México \\ E. Figueras \\ Laboratorio de Caracterización de Microsistemas, Instituto de Microelectrónica de Barcelona IMB-CNM (CSIC) \\ Cerdanyola, Barc. 08193, Spain \\ (Received: October 25th, 2016; Accepted: February 15th, 2018)
}

\begin{abstract}
This document presents the finite element modeling using ANSYS to obtain the thermal resistance of a MEMS thermal sensor. Additionally, the document describes a thermoelectrical characterization to find the sensor performance parameters. For modeling purposes, we divided the thermal sensor into four different thickness zones. We analyzed three different models, the first includes all materials layers, the second involves an equivalent thermal conductivity and an equivalent thickness for each zone, and the proposed model besides using an equivalent thermal conductivity by zone also considers the same thickness for all zones to reduce simulation time and to optimize thermal sensor design parameters. The first model evaluates three different boundary conditions, while the second and third models consider two different thermopile wide strips. The thermal resistance of the proposed model has a relative error of $11 \%$ in relation to the experimental value. The model, considering all layers and heat power applied to the surface as boundary conditions, has the lowest error (9\%), while models considering the thermopile strips width have shown a higher error, 67\%. As a result, the proposed model for heat transfer analysis simplifies complex geometries and reduces simulation time.
\end{abstract}

\section{Introduction}

Calorimeters are essential tools used to find thermodynamic properties (i.e. changes in enthalpy $\Delta H$, Gibbs free energy $\Delta G$, entropy $\Delta S$ and heat capacity $\Delta C_{p}$ ) in a wide range of scientific fields such as chemical, biochemical, biology, biotechnology, pharmacology, and nanoscience [1-4]. Usually, microcalorimeters include a reaction chamber, a temperature sensor to measure the heat released or absorbed by the chemical reaction of the samples in the reaction chamber [4] and also include heaters for device calibration; moreover, differential microcalorimeters use an additional chamber as a reference chamber [5]. Some calorimeters use thermistors [6,7] or thermopiles [5,8-9] as thermal sensors, however, thermopiles have higher sensitivity than thermistors due to the absence of an electrical current [4]. Since thermopiles convert thermal energy into electrical, they have zero offset and the flicker noise could not affect static detection [10]. Besides, thermopiles do not require biasing; thus, there is no power dissipation neither interference caused by power supplies [13]. Thermopile's differential temperature measurements reduce or even remove common-mode interferences such as room temperature fluctuation. In addition, thermopiles have been widely used as thermal vacuum sensor [14] and gas sensing [10,15-17]. In calorimeters, the thermal resistance of thermal sensor converts the heat released by an exothermic chemical reaction into a temperature gradient [17]. Therefore, the thermal resistance must be known to calculate analyte's * $\underline{\text { mgomez@uacj.mx }}$ concentrations $[5,8,17]$ to model a differential calorimeter and to optimize the thermopile design. Due to the complex geometry of thermal sensors, usually, thermal resistance is experimentally found. Nevertheless, thermal resistance is also obtained by Finite Element Method (FEM) [10,18], thermal sensor models are based on one-dimensional Fourier's stationary heat equations, so these models frequently divide the thermal sensor in two $[15,18]$ or three zones [10], and take into account radiative power $[10,15]$ or heater power as heat source [18].

The present paper discusses three 3D finite element models analyzed in ANSYS to calculate the thermal resistance of the MEMS thermal sensor. We divided the thermal sensor into four zones, instead of two or three zones as in $[10,15,18]$ and since we added an SU-8 layer, every zone had different thickness. The first model includes all sensor's layers, the second model settled an equivalent thermal conductivity, and an equivalent thickness for each zone as in $[10,15,18]$. The third model offers a new approach to reduce the simulation time and to optimize the thermal sensor design parameters, thus besides an equivalent thermal conductivity we propose an equivalent thickness of same height for all zones. Also, we analyzed three different ways to apply or generate heat for the first model: on a surface $[10,15,18]$, in volume, or applying an electrical current to the heater. As well as we consider different thermopile strip widths for the second and third models. This work also describes the thermoelectrical characterization of the thermal sensor to get the device performance parameters and explains some FEM models to 


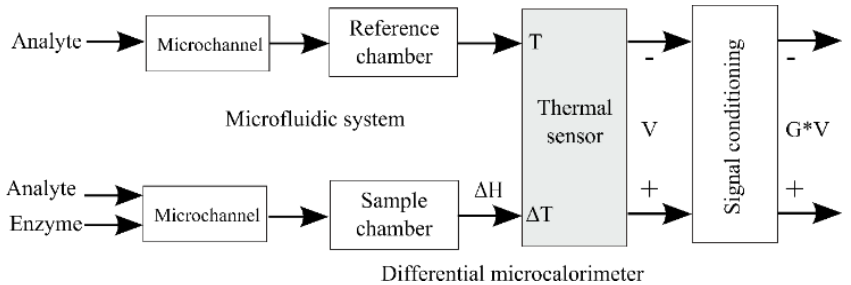

Figure 1. MEMS thermal sensor for analyte measurement schematic.

find thermopile parameters such as temperature sensitivity and electrical resistance.

\section{Operating principle}

Figure 1 shows a MEMS differential thermal sensor for analyte measurement (i. e. glucose), which consists of a microfluidic system and a differential calorimeter. An infusion pump supplies analyte and enzyme solutions by two different inlets to the microfluidic system, then both solutions mix to each other through the microchannel, afterwards, the enzymatic reaction takes place in the reaction chamber. Since the reference chamber holds its temperature, the thermal sensor measures the temperature gradient and generates an electrical potential which signal must be filtered and amplified through a signal conditioning. An enzymatic reaction generates the heat $q$ proportionally to the reaction molar enthalpy $n_{m} \Delta H$ where the number of moles $n_{m}$ is proportional to the concentration of the created product $\left[C_{P}\right]$ or to the consumed reactant $\left[C_{S}\right]$ in a reaction volume $V$

$$
q=\left[C_{P}\right] V \Delta H=\left[C_{S}\right] V \Delta H
$$

Heat flow $d q / d t$ or thermal power $\Delta P$ is directly proportional to the product formation rate $d\left[C_{P}\right] / d t$ or to the substrate consumed rate $-d\left[C_{S}\right] / d t$, also known as reaction rate constant or reaction rate coefficient $k$. When substrate concentration is consumed it has an exponential decay, so heat flow is

$$
\dot{q}=\Delta P=V \Delta H\left[C_{S 0}\right] e^{-k t}
$$

Sensor's thermal resistance $R_{t h}$ converts the thermal power of the enzymatic reaction to a temperature gradient as $\Delta T=$ $\Delta P R_{t h}$. Hence, a differential thermal sensor measures the temperature gradient using thermopiles, which consist of thermocouples connected electrically in series and thermally in parallel. Thermocouples are based on Seebeck effect, so when two dissimilar materials are joined together by one end (hot region) and a temperature gradient $\Delta T$ appears between the hot and cold regions, the thermocouple generates an open circuit voltage $\Delta V$. Thus, the electrical potential $U_{t p}$ generated by the thermopile is $U_{t p}=n \alpha \Delta T=S_{t p} R_{t h} \Delta P$

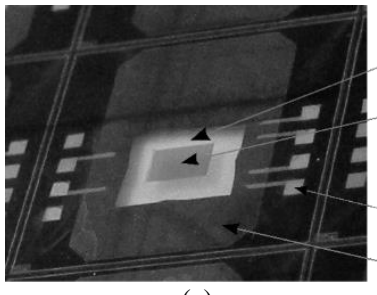

(a)

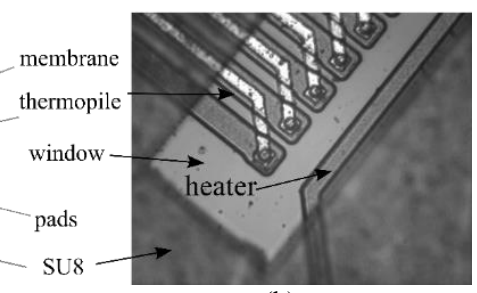

(b)
Figure 2. Thermal sensor images of a (a) macroscopic view and (b) hot junction and heater microscopic view. where $n$ is the number of thermocouples, $\alpha$ is the Seebeck coefficient, and the product $n \alpha$ is the thermopile sensitivity denoted as $S_{t p}$. Therefore, thermopile's electrical potential is directly proportional to the consumed substrate concentration

$$
U_{t p}=S_{t p} R_{t h} V \Delta H\left[C_{S 0}\right] e^{-k t}
$$

While thermal resistance is calculated as $R_{t h}=L / \kappa A$, where $L$ is the length, $\kappa$ is the thermal conductivity and $A$ is the sensor area, the complex design of the thermal sensor makes necessary to obtain experimentally the thermal resistance [5,8,17].

Sensor's performance is determined by several parameters such as device's responsivity [5,8] also known as heat power sensitivity [12,14] or thermopile's electrical sensitivity [10] $S_{P}$, defined as the ratio between the thermopile output voltage $U_{t p}$ and the power gradient, or as the product of the thermopile sensitivity and the thermal resistance

$$
S_{P}=\frac{U_{t p}}{\Delta P}=S_{t p} R_{t h}
$$

Thermal noise is the main thermopile noise source which is given by $u_{n}=\sqrt{4 k_{B} T R_{t p} \Delta f}$, where $k_{B}$ is the Boltzmann's constant, $R_{t p}$ is the thermopile's resistance, $T$ is the ambient temperature and $\Delta f$ is the bandwidth. So additional performance parameters are specified by the thermopile noise source, such parameters are SNR (Signal to Noise Ratio), $S N R=U_{t p} / u_{n}$, NEP (Noise Equivalent Power), $\quad N E P=u_{n} / S_{P}, \quad$ NETD (Noise Equivalent Temperature Detection), NETD $=u_{n} / S_{t p}$, and detectivity (D), $D=S N R / \Delta P=S_{P} / u_{n}$.

\section{Thermal sensor design}

The thermal sensor area is a structure of $10 \mathrm{~mm} \times 10 \mathrm{~mm}$. Silicon substrate integrates a thermopile and two heaters as a single thermal sensor (Figure 2). The thermopile consists of 78 thin film n-type polysilicon and aluminum thermocouples. Heaters are of n-type polysilicon which can be used for device characterization, chambers temperature control or device calibration. The thermal sensor is over a thin membrane to minimize the sensor's thermal mass and to reduce the time response [5]. A polymer layer is on top of the thermal sensors to obtain a smooth surface. The thermal sensor includes a small window around the thermopile junctions to preserve the heat nearby the thermopile junctions. Electrical connections are of aluminum.

We used a back side polished p-type wafer with <100> orientation, $100 \mathrm{~mm}$ diameter, $500 \mu \mathrm{m}$ thickness and nominal resistivity 4-40 $\Omega$-cm in a six-level manufacturing process. At zero level, we formed the membrane layer and back-side layer; a $50 \mathrm{~nm} \mathrm{SiO}$ layer and a $300 \mathrm{~nm} \mathrm{Si}_{3} \mathrm{~N}_{4}$ layer constitute the membrane layer. At first level, we defined polysilicon strips (1.2 $\mu \mathrm{m}$ thickness). At second level, we created contacts definition and a $0.8 \mu \mathrm{m} \mathrm{SiO}_{2}$ layer for electrical isolation. The third level is metallization, so we added a $0.8 \mu \mathrm{m} \mathrm{Al} / \mathrm{Cu}$ layer. At fourth level, we performed passivation etch of a $0.3 \mu \mathrm{m}$ oxide layer and a $0.5 \mu \mathrm{m}$ nitride layer. At fifth level, we defined back-side windows. Finally, at sixth level, we added a $25 \mu \mathrm{m}$ SU-8 layer. 


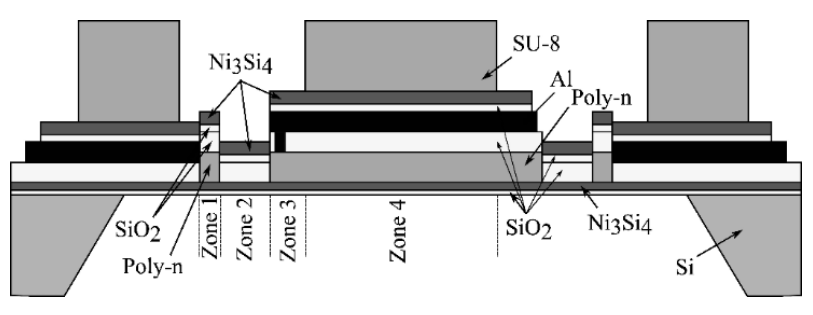

Figure 3. Cross section view of thermal sensor structure.

\section{Thermal modeling}

Figure 3 shows the thermal sensor cross-section view. Heater, membrane, insulation and passivation layer represent zone-1, where heater generates heat flux, $q_{0}$. Zone-2 separates the heater and thermopile hot junctions, formed by membrane, insulation and passivation layers. Thermopile's hot junctions form zone-3, which includes membrane, insulation and passivation layers and thermal elements (n-polySi/Al). Zone-3 layers and an additional SU-8 layer form zone- 4 . Because of symmetry we only considered the half-length heater, so zone-1 length is $3 \mu \mathrm{m}$, zones 2,3 and 4 have $22 \mu \mathrm{m}, 27 \mu \mathrm{m}$ and $1944 \mu \mathrm{m}$ lengths, respectively. Additionally, we defined a width of $1372 \mu \mathrm{m}$ for all zones, so, we only use length $l_{n}$ and thickness $d_{n}$, as zone dimensions, where $n$ stands for zone number.

In order to find the sensor's thermal resistance, we developed three different models for ANSYS simulations, named ANSYS-TC, ANSYS-4Z, and ANSYS-ME. In ANSYS-TC model we included all material's layers. In ANSYS-4Z model we calculated an equivalent thermal conductivity and equivalent thickness for each zone. In ANSYS-ME model we calculated an equivalent thermal conductivity and set up an equivalent thickness where all zones had the same height. The boundary conditions for all models are ambient temperature of $300 \mathrm{~K}$ and air convection coefficient $h$ of $10 \mathrm{~W} / \mathrm{m}^{2} \mathrm{~K}$. ANSYS-TC model includes all layers of the actual thermal sensor; to optimize meshing we divided ANSYS-TC model into volumes and used the same width to all layers. We set up three different boundary conditions to analyze ANSYS-TC model, applied heat power on the zone-1 lateral surface (ANSYS-TCqA), supplied an electrical current to the heater in ANSYS-TCiR model, and used the heat generation function in ANSYS-TChg model, so, the heather volume generated the heat power. The SOLID90 (3D 20-node thermal solid) was the main element we chose for ANSYS simulations except for the ANSYSTCiR model where we used the SOLID226 (3D 20-node couple-field solid). For each zone, we calculated an equivalent thermal conductivity $k_{e n}$ and an equivalent thickness, $d_{n}$, for ANSYS-4Z model, as in $[15,20]$, given by

$$
\begin{aligned}
& d_{n}=\sum d_{j} \\
& k_{e n}=\frac{\sum_{j=1}^{n} k_{j} w_{j}}{d_{n}}
\end{aligned}
$$

Subscript $j$ relates each material layer, $w_{j}$ is the coverage coefficient [12] defined by the material layer and zone width ratios. We applied a heat flow, $q_{0}$, on the zone- 1 lateral surface. Also, we analyzed two different conditions, by using the same width for all layers (ANSYS-4ZwT model) and a different width for the thermopile strips (ANSYS-4ZwTp model). For the ANSYS-ME model we specified the same thickness to all zones, so we settled a new equivalent thickness and a new equivalent thermal conductivity, our innovation. Like ANSYS-4Z model we analyzed two different conditions, the same layer width (ANSYS-MEwT model) and a different width for the thermopile strips (ANSYS-MEwTp model).

\section{Experimental details}

\section{Thermoelectrical Characterization}

For this work we characterized five chips, labeled A, B, C, $\mathrm{D}$, and $\mathrm{E}$; since only chip D was wire bonding, we tested the other chips using probe station tips. We used an Agilent E3645 power supply and an Agilent 34411A multimeter for electrical resistance measurement of chips A, B, and C. To characterize the chip $\mathrm{D}$, we used a portable infrared camera Fluke ${ }^{\circledR}$ Ti25, an InfiniiVision DSO-X 3054A oscilloscope and an Agilent E3631 power supply. To obtain the electrical resistance of the heather and thermopile of chip D, we applied a voltage range from $-5 \mathrm{~V}$ to $+5 \mathrm{~V}$, with $1 \mathrm{~V}$ steps. We got the electrical resistance by the slope of the regression line. By using the four-wire resistance measurement technique, we found the heater and thermopile electrical resistance of chips A, B, C, and E. To obtain the thermal sensor's heat power and temperature sensitivities we used a joule heating experiment, where a $\mathrm{CC}$ source drives the heater next to the hot junction. We only obtained thermopile's sensitivity for chip D. We applied a voltage range from $2 \mathrm{~V}$ to $10 \mathrm{~V}$ with $0.5 \mathrm{~V}$ steps to the heater, then we measured the temperature with an infrared camera and the thermopile's voltage using the oscilloscope to obtain device responsivity. In addition to the ANSYS models we described before, we simulated the thermopile to get its electrical resistance and sensitivity, considering two thermopile's materials.

From literature we got the Seebeck coefficient of -200 $\mu \mathrm{V} / \mathrm{K}$ and $-1.7 \mu \mathrm{V} / \mathrm{K}$ for $\mathrm{n}$-type polysilicon [21] and aluminum [22], respectively; as well as other material properties such as thermal conductivity, mass density and heat capacity [21]. To obtain the electrical resistance of heather and thermopile we supplied an electrical current of $100 \mu \mathrm{A}$ to each of them, and we calculated the output voltage according to Ohm's Law. To get thermopile sensitivity we applied a temperature difference of $100 \mathrm{mK}$ to the hot and cold thermopile's junctions to measure the thermopile's output voltage.

\section{Results and discussion}

\section{Electrical resistance}

We calculated the thermocouple's electrical resistance of $2.7 \mathrm{k} \Omega$ based on its geometry considering an electrical resistivity of $0.032 \mu \Omega \cdot \mathrm{m}$ [22] and $16 \mu \Omega \cdot \mathrm{m}$ [21] of aluminum and n-type polysilicon, respectively, thus the thermopile's electrical resistance was $209.3 \mathrm{k} \Omega$. Heater's electrical resistance was $3.5 \mathrm{k} \Omega$ considering n-type 

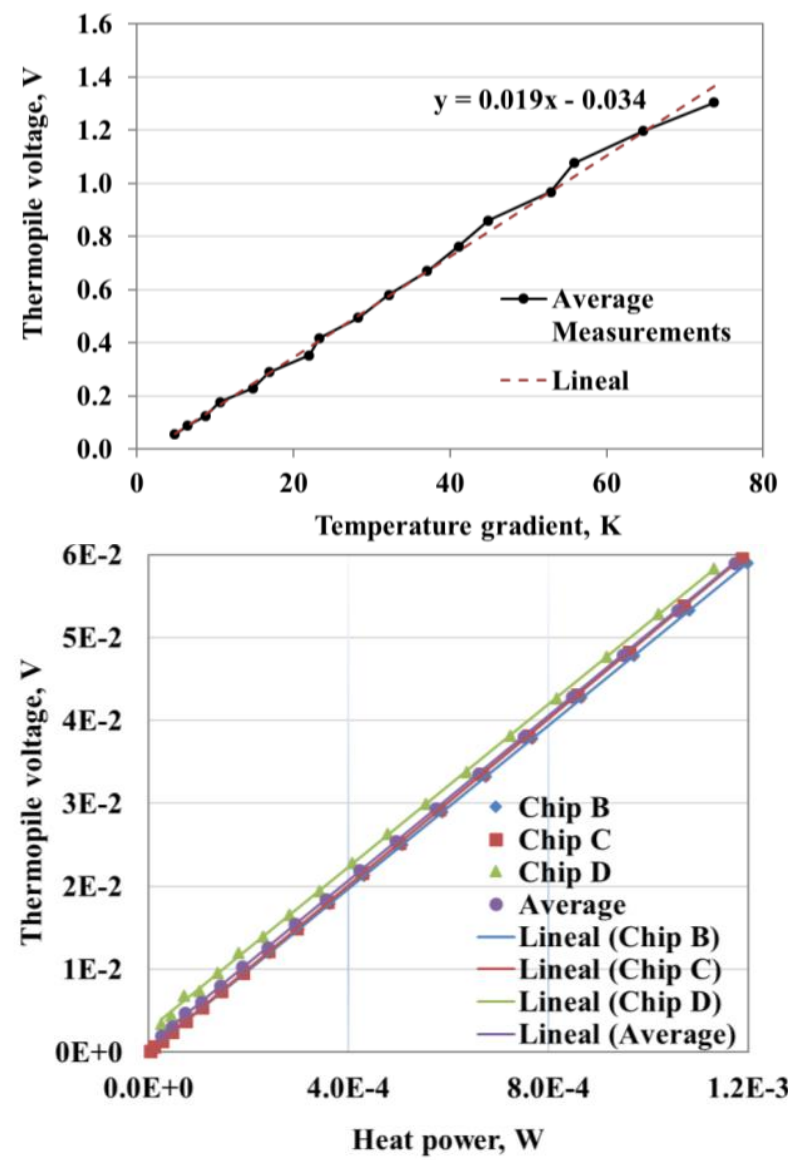

Figure 4. Chip D experimental measurements, a) temperature sensitivity, b) heat power sensitivity.

polysilicon, $6 \mu \mathrm{m}$ width, $8 \mu \mathrm{m}$ thickness and $1590 \mu \mathrm{m}$ length. Since electrical connections are of aluminum we discarded its resistance. Due to thermopile's complex geometry and our limited computational resources we only could simulate a maximum of 70 thermocouples in ANSYS; therefore, to confirm thermopile's linearity, we carried out simulations using 1, 10, 30 and 70 thermocouples. In ANSYS we obtained a thermocouple's electrical resistance of $2.7 \mathrm{k} \Omega$, so thermopile's electrical resistance was $209.2 \mathrm{k} \Omega$, yielding an error of $0.05 \%$ compared to the calculated value. The average electrical resistance we measured was $221.4 \mathrm{k} \Omega$ with a standard deviation of $5.5 \mathrm{k} \Omega$, thus the relative error was $5.7 \%$. The heater's electrical resistance measured was $3.6 \mathrm{k} \Omega$, so the relative error was $0.1 \%$.

\section{Temperature sensitivity}

Seebeck coefficient of one thermocouple was $198.3 \mu \mathrm{V} / \mathrm{K}$, so the calculated thermopile sensitivity was $15.47 \mathrm{mV} / \mathrm{K}$. To experimentally obtain the temperature sensitivity of chip D, we performed three tests, so we got the thermopile's sensitivity average by the slope of the regression line, which was $18.98 \mathrm{mV} / \mathrm{K}$ (Figure 4a), with a relative error of $18.5 \%$. We completed ANSYS thermoelectric analysis using only 70 thermocouples because of thermopile complex geometry and limited computational resources. Nevertheless, Seebeck coefficient is a mass property and has no shape dependency, thus if we reduce thermocouple's length, its sensitivity
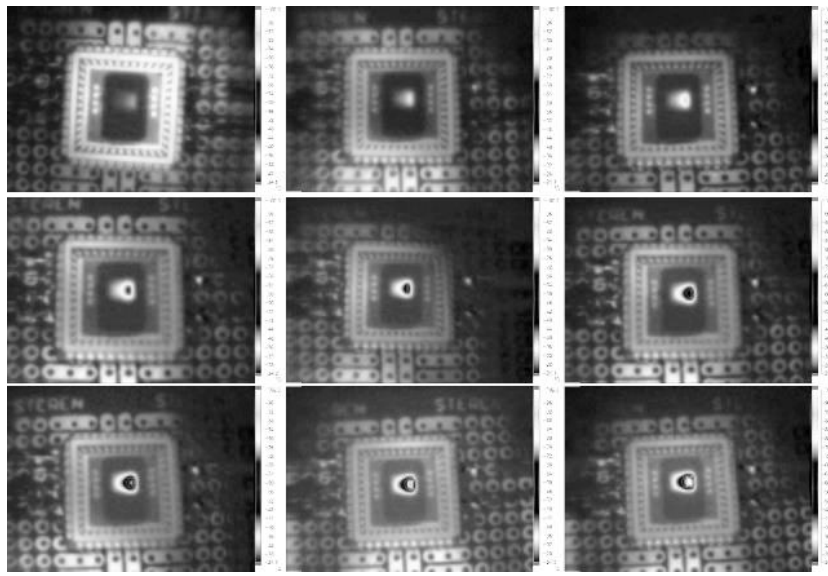

Figure 5. Chip D thermal map. Temperature scale is $24.1-102^{\circ} \mathrm{C}$.

remains the same. Therefore, we performed ANSYS simulations for 60 thermocouples of different strip lengths of $1993 \mu \mathrm{m}, 997 \mu \mathrm{m}$ and $498 \mu \mathrm{m}$, getting the same temperature sensitivity of $15.469 \mathrm{mV} / \mathrm{K}$, yielding a $0.01 \%$ relative error to the calculated value, also reducing the simulation time from 48 hours, 16 hours to less than 2 hours, respectively.

\section{Heat power sensitivity}

Figure $4 \mathrm{~b}$ shows heat power vs thermopile output voltage for chips $\mathrm{B}, \mathrm{C}$, and $\mathrm{D}$, by the slope of the regression line, we found values of $49.3 \mathrm{~V} / \mathrm{W}, 50.2 \mathrm{~V} / \mathrm{W}$ and $49 \mathrm{~V} / \mathrm{W}$, respectively. We also tested a chip without the hole under the thermopile and we got a responsivity of $0.1 \mathrm{~V} / \mathrm{W}$, proving that substrate thermal mass reduces the heat power sensitivity.

\section{Thermal resistance}

To find the thermal resistance we supplied to the heater of chip D a voltage range of $2-10 \mathrm{~V}$ with $1 \mathrm{~V}$ steps and measured the temperature gradient by an infrared camera; figure 5 depicts the chip D thermal map, to point out the heater temperature rising we used the same temperature scale. Figure 6 shows the Chip D thermal resistance by the slope of the regression line plotting heater power $v s$ temperature gradient, so finding a thermal resistance of 2427 K/W. Furthermore, we calculated an average thermal resistance of $2636 \mathrm{~K} / \mathrm{W}$ by considering sensor responsivity $S_{P}$ and temperature sensitivity $S_{T p}$ where $R_{t h}=S_{P} / S_{T p}$.

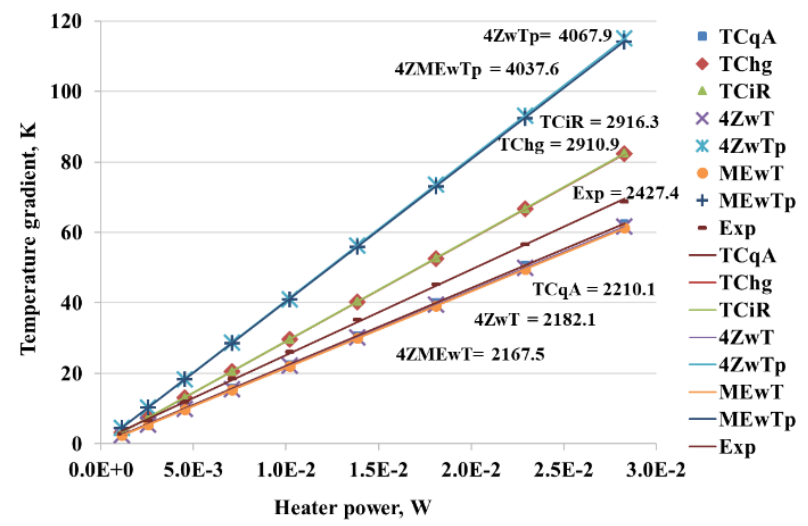

Figure 6. Thermal resistance. 
Table 1. Zone's equivalent thermal conductivity [W/mK] used in ANSYS models.

\begin{tabular}{ccccc}
\hline Zone & 4ZwT & 4ZwTp & MEwT & MEwTp \\
\hline 1 & 21.1 & 21.1 & 21.1 & 21.1 \\
2 & 10.7 & 10.7 & 6.6 & 6.6 \\
3 & 64.4 & 28.1 & 80.8 & 35.2 \\
4 & 9.1 & 4.1 & 83.2 & 37.6 \\
\hline
\end{tabular}

ANSYS models

In $[10,15,18]$ used 2-D models to analyze thermal sensors, instead we managed 3-D ANSYS elements to apply an electrical current. In ANSYS-TCqA model, we supplied the heat power to the lateral area of zone 1, finding a thermal resistance of $2210 \mathrm{~K} / \mathrm{W}$ with a $9 \%$ of relative error, which is the lowest error of all models. For ANSYS-TChg and ANSYS-TCiR models the heater volume generated the heat power, showing an analogous behavior, with thermal resistance values of $2911 \mathrm{~K} / \mathrm{W}$ (TChg) and $2916 \mathrm{~K} / \mathrm{W}$ (TCiR), respectively, with a relative error of $20 \%$. In ANSYS-4Z models we calculated an equivalent thermal conductivity and an equivalent thickness for each zone as in $[10,15,18]$. Besides, we considered two different thermopile width dimensions: the same for all layers (ANSYS-4ZwT model) and a different thermopile strips width (ANSYS4ZwTp model). As a result, we found that the ANSYS4ZwTp model thermal resistance almost doubled the ANSYS-4ZwT model, $4068 \mathrm{~K} / \mathrm{W}$, and $2181 \mathrm{~K} / \mathrm{W}$, respectively. Since thermal resistance is inversely proportional to cross-section area where heat transfer takes place if we shorten the thermopile width strips, then the thermal resistance increases. The proposed ANSYS-ME model, besides an equivalent thermal conductivity, defines the same height for all zones specifying a new equivalent thickness. As in ANSYS-4Z models, we analyzed the same conditions considering different widths. Table 1 shows equivalent thermal conductivities of four zones used in ANSYS-4Z and ANSYS-ME models. We used an equivalent thickness of $3.15 \mu \mathrm{m}$ for ANSYS-ME model. The ANSYS-MEwTp model thermal resistance almost doubled the ANSYS-MEwT model, $4038 \mathrm{~K} / \mathrm{W}$, and $2168 \mathrm{~K} / \mathrm{W}$, respectively, as in ANSYS-4Z models. ANSYS-TCqA, ANSYS-4ZwT, and ANSYS-MEwT models had the lowest relative error $9 \%, 10 \%$ and $11 \%$, respectively. As a result, heat transfer analysis on the proposed model simplifies

Table 2. Thermal resistance and responsivity obtained from ANSYS models.

\begin{tabular}{lcccc}
\hline $\begin{array}{c}\text { ANSYS } \\
\text { Model }\end{array}$ & $\begin{array}{c}\mathbf{R}_{\text {th }} \\
(\mathbf{K} / \mathbf{W})\end{array}$ & $\begin{array}{c}\mathbf{S}_{\mathbf{p}} \\
(\mathbf{V} / \mathbf{W})\end{array}$ & $\begin{array}{c}\text { \% Error } \\
\mathbf{R}_{\text {th }}\end{array}$ & $\begin{array}{c}\text { \% Error } \\
\mathbf{S}_{\mathbf{p}}\end{array}$ \\
\hline TCqA & 2210 & 43 & 9 & 31 \\
TChg & 2911 & 45 & 20 & 9 \\
TCiR & 2916 & 45 & 20 & 9 \\
4ZwT & 2182 & 34 & 10 & 32 \\
4ZwTp & 4068 & 63 & 67 & 27 \\
4ZMEwT & 2167 & 33 & 11 & 32 \\
4ZMEwTp & 4037 & 62 & 66 & 26
\end{tabular}

Table 3. Thermal sensor parameters.

\begin{tabular}{lccc}
\hline \multicolumn{1}{c}{ Parameter } & Calculated & Measured & $\begin{array}{c}\text { Relative } \\
\text { error, \% }\end{array}$ \\
\hline $\begin{array}{l}\text { Thermopile electrical } \\
\text { resistance }(\mathrm{k} \Omega)\end{array}$ & 209 & 221 & 6 \\
$\begin{array}{l}\text { Heater electrical } \\
\text { resistance }(\mathrm{k} \Omega)\end{array}$ & 3.533 & 3.536 & 0.1 \\
$\begin{array}{l}\text { Thermopile sensitivity } \\
(\mu \mathrm{V} / \mathrm{K})\end{array}$ & 15 & 19 & 18 \\
$\begin{array}{l}\text { Thermal resistance }(\mathrm{K} / \mathrm{W}) \\
(\mathrm{ANSYS}-\mathrm{MEwT} \text { model})\end{array}$ & 2167 & 2427 & 11 \\
$\begin{array}{l}\text { Responsivity }(\mathrm{V} / \mathrm{W}) \\
(\mathrm{ANSYS}-\mathrm{MEwT} \text { model})\end{array}$ & 33 & 50 & 32 \\
$\begin{array}{l}\text { Thermal noise, }(1 \mathrm{~Hz}) \\
(\mathrm{nV} / \sqrt{\mathrm{Hz}})\end{array}$ & 59 & 60 & 3 \\
$\begin{array}{l}\mathrm{NETD}(\mu \mathrm{K}) \\
\mathrm{NEP}(\mathrm{nW}) \\
(\mathrm{ANSYS}-\mathrm{MEwT} \text { model})\end{array}$ & 2 & 3.2 & 18 \\
$\begin{array}{l}\mathrm{D}(\mathrm{G} \sqrt{\mathrm{Hz}} / \mathrm{W}) \\
\mathrm{SNR}(\Delta \mathrm{T}=10 \mathrm{mK})\end{array}$ & 57 & 1 & 43 \\
\hline
\end{tabular}

complex geometries and reduces simulation time. Besides, we could use 2D elements because these models do not need a 3D heater for heat transfer. ANSYS-TChg and ANSYS-TCiR models had a responsivity of $45 \mathrm{~V} / \mathrm{W}$ and a 9\% relative error. ANSYS-TCqA, ANSYS-4ZwT and ANSYS-MEwT models had a responsivity of $43 \mathrm{~V} / \mathrm{W}, 34$ $\mathrm{V} / \mathrm{W}$ and $33 \mathrm{~V} / \mathrm{W}$, with a relative error of $31 \%, 32 \%$ and $32 \%$, respectively. Since responsivity is directly related to thermal resistance, ANSYS-4ZwTp and ANSYS-MEwTp models responsivity almost doubled the ANSYS-4ZwT, and ANSYS-MEwT models, $63 \mathrm{~V} / \mathrm{W}$ and $62 \mathrm{~V} / \mathrm{W}$, respectively; reducing the relative error to $27 \%$ and $26 \%$, respectively. Table 2 summarize thermal resistance and responsivity obtained from ANSYS models.

\section{Thermal sensor parameters}

Table 3 summarizes the thermal sensor parameters. Since ANSYS-MEwT model is our innovation, we compared it to measured values. The lowest temperature gradient that the thermal sensor can measure is $3.2 \mu \mathrm{K}$. The least power gradient that the thermal sensor can detect is $1.2 \mathrm{nW}$. For a temperature gradient of $10 \mathrm{mK}$, it has a high SNR of 3134 . The device resolution bandwidth was $2 \mathrm{nW}$, which is lower than literature $[8,11]$. The thermal noise over $1 \mathrm{~Hz}$ was $60 \mathrm{nV}$ which is close to previous reports $[5,18,13]$. In general, thermal sensors used as calorimetric biosensors have less than $10 \mathrm{~V} / \mathrm{W}$ device responsivities [5,8-9,11,23], because all of them include their microfluidic system for device calibration. On the other hand, IR sensors have higher responsivities as $70 \mathrm{~V} / \mathrm{W}$ [10], because they considered the air during simulation or experimental measurements. Based on the Seebeck coefficients from the literature we found an $18 \%$ relative error for thermopile sensitivity. Since we used the same material properties thermopile electrical resistance obtained by ANSYS and the calculated value were similar. 


\section{Conclusions}

We proved that finite element analysis simplifies the operations to get the thermal sensor parameters. Since the aspect ratio of thermopiles needs many nodes to solve, so we proposed to define zones for different layers of material to replace the exact geometry and to define the same height to all zones, to get an equivalent thermal conductivity and an equivalent thickness. Though we got an error of $11 \%$ for thermal resistance, we developed a new way to simplify the finite element analysis that we can use to evaluate the design of calorimeters. However, the electrical resistance needs considering the whole thermopile using 3-D thermoelectrical elements. Thermopile linearity allows reducing simulation time by decreasing the number of thermocouples. Likewise, we may get thermocouple's sensitivity in less time by shortening the thermocouple lengths. Once we experimentally measured heater's electrical resistance we also got it by finite element analysis, choosing from literature the material properties that yield the lowest error. Finally, parameters such as thermal noise and resolution guarantee that we could use the thermal sensor for glucose measurement. Though, if the thermal sensor includes the microfluidic system the device performance changes.

\section{Acknowledgements}

Consejo Estatal de Ciencia y Tecnología de Jalisco (COECYTJAL), under project number 23-2008-335, supported this work.

\section{References}

[1]. P. Gill, T. Moghadam, B. Ranjbar, J. Biomol. Tech. 21, 167 (2010).

[2]. L.D. Hansen, J. Rusell, T. Choma, Cell Biochem. Biophys. 49, 125 (2007).

[3]. K.N. Marsh, J.B. Ott, C.J. Wormald, H. Yao, I. Hatta, P.M. Claudy, S. Van Herwaarden, in: Measurements of the Thermodynamic Properties of Single Phases, Eds. A.R.H.
Goodwin, K.N. Marsh, W.A. Wakeham, (IUPAC, Elsevier, 2003) p. 368 .

[4]. M.K. Khaw, F. Mohd-Yasin, N.T. Nguyen, Microelect. Eng. 158, 107 (2016).

[5]. L. Wang, D.M. Sipe, Y. Xu, Q. Lin, J. Microelectromech. S. 17, $318(2008)$.

[6]. B. Xie, K. Ramanathan, B. Danielsson, In: Thermal Biosensors, Bioactivity, Bioaffinitty, Eds. P.K. Bhatia et al. (Springer-Verlag Berlin Heidelberg, 1999) pp 1-33.

[7]. C.G. Velve, F. Bertholle, M. Le Berre, S. Meance, L. Malaquin, J.J. Greffet, Y. Chen, Microelectron. Eng. 85, 1367 (2008).

[8]. Y. Zhang, S. Tadigadapa, Biosens. Bioelectron. 19, 1733 (2004).

[9]. T. Adrega, A.W. van Herwaarden, Sens. Actuators, A 167, 354 (2011).

[10]. C. Escriba, E. Campo, D. Estève, J.Y. Fourniols, Sens. Actuators, A 120, 267 (2005).

[11]. C.M. Johnston, B.P. Ruddy, P.M.F. Nielsen, A.J. Taberner, Am. J. Physiol. Heart. Circ. Physiol. 309, H318 (2015).

[12]. T.P. Huynh, Y. Zhang, C. Yehuda, Sensors 15, 3351 (2015).

[13]. A.W. van Herwaarden, D. C. van Duyn, $\underline{\text { Sens. Actuators, A }}$ 22, 621 (1990).

[14]. D. Randjelović, M.P. Frantlović, B.L. Miljković, B.M. Popović, Z.S. Jakšić, Vacuum 101, 118 (2014).

[15]. A.G. Kozlov, Sens. Actuators, A 75, 139(1999).

[16]. D. Randjelović, Ž. Lazić, M. Popović, M. Matić, Proceedings 28th Intl. Conf. on Microelectron. 12821610 (2012).

[17]. A.W. van Herwaarden, P. M. Sarro, J.W. Garadner, P. Bataillard, Sens. Actuators, A 43, 24 (1994).

[18]. D. Randjelović, A. Petropoulos, G. Kaltsas, M. Stojanović, Ž. Lazić, Z. Djurić, M. Sens. Actuators, A 141, 404 (2008).

[19]. M. Gómez-Franco, A. Ramírez-Treviño, WADED2011, 1st workshop on analog and digital electronic design (2011).

[20]. F. Volklein, H. Baltes, Sens. Actuators, A 36, 65 (1993).

[21]. J. Xie, C. Lee, M.F. Wang, Y. Liu, H. Feng, J. Micromech. Microeng. 19, 125029 (2009).

[22]. R. Rubio Bonilla, PhD thesis "Nueva Arquitectura para un nuevo analizador compacto de gases basado en una matriz de microsensores de infrarrojo no específico" (Universitat de Barcelona, 2007).

[23]. J. Lerchner, A. Wolf, G. Wolf, I. Fernandez, Thermochim. Acta 446, 168 (2006).

(C) 2018 by the authors; licensee SMCTSM, Mexico. This article is an open access article distributed under the terms and conditions of the Creative Commons Attribution license (http://creativecommons.org/licenses/by/4.0/). 